\title{
Precursory influence of the Antarctic Oscillation on the onset of Asian summer monsoon
}

\author{
GAO Hui ${ }^{*}$, LIU YunYun, WANG YongGuang \& LI WeiJing \\ National Climate Center, China Meteorological Administration, Beijing 100081, China
}

Received May 24, 2012; accepted August 2, 2012; published online September 7, 2012

\begin{abstract}
The Asian summer monsoon (ASM) begins firstly over the Indo-China Peninsula in early May and over the South China Sea (SCS) in mid-May. The different monsoon onset dates can exert distinct effects on the summer rainfall in Asia. Statistical results indicate that the Antarctic Oscillation (AAO) in the boreal winter has a significant precursory influence on the ASM onset dates. In stronger AAO years, both the Mascarene high and the Australia high in March are stronger owing to the "see-saw" structure of atmospheric circulation over the subtropics and higher latitudes in the Southern Hemisphere, and the tropical intertropical convergence zone (ITCZ) is deeper. Thus, the pressure gradient between the subtropical and tropical regions increases in spring. As a result, the Somalia cross-equatorial flow (SCEF) occurs earlier, strengthens, and enhances the westerlies over the tropical Indian Ocean. The enhanced westerlies impel an eastward withdrawal of the western Pacific subtropical high and intensify the convergence and rising motion at the lower troposphere, accelerating the burst of ASM. Differently, weaker AAO weakens the pressure gradient between the tropical and subtropical regions and delays the establishment of SCEF, resulting in a delayed onset of ASM. This study extends the leading time of seasonal forecast of ASM onset from the previous spring to winter and provides useful information about precursory signals in climate prediction operation.
\end{abstract}

\section{Asian summer monsoon, Indo-China Peninsula, South China Sea, Antarctic Oscillation, Somalia cross-equatorial flow}

Citation: Gao H, Liu Y Y, Wang Y G, et al. Precursory influence of the Antarctic Oscillation on the onset of Asian summer monsoon. Chin Sci Bull, 2013, 58: 678-683, doi: 10.1007/s11434-012-5455-x

As a leading mode of the extratropical atmosphere in the Southern Hemisphere (SH), the Antarctic Oscillation (AAO) displays a "sea-saw" pattern between the pressures or geopotential heights in the subtropics and higher latitudes. It has a close relationship with other circulation members in $\mathrm{SH}$ such as the South Polar vortex, the double westerly jet, the Australia high $(\mathrm{AH})$, and the Mascarene high $(\mathrm{MH})$. Although its first illustration can be found nearly a century ago [1-5], its influence on the Northern Hemisphere (NH) climate has not been studied till recently. Owing to the limitation in datasets at the SH high latitudes, nearly all studies have focused only on the subtropical branch of AAO, especially the MH and the AH. Since the 1980s, Chinese meteorologists have investigated the interactions of zonal and meridional circulations between East Asia and Australia

\footnotetext{
*Corresponding author (email: gaohui@cma.gov.cn)
}

$[6,7]$. For example, the cold air in one hemisphere can significantly affect the monsoon weather and climate in the other hemisphere [8]. Results also show the key role of $\mathrm{MH}$ in the East Asian summer monsoon (EASM) and in the interaction between the two hemispheres $[9,10]$. He and Chen [11] analyzed the influence of the quasi-40-day low-frequency oscillation (LFO) in the middle latitudes in SH on the Asia summer monsoon (ASM). The authors pointed out that the cold air in SH firstly strengthened the $\mathrm{MH}$, the $\mathrm{AH}$, and the westerly flow over the south of the two highs through meridional propagation of the LFO, then enhanced the southeasterly flow to the north of the highs and the cross-equatorial flow (CEF), and finally accelerated the burst of ASM. The strengthened CEF especially the Somalia cross-equatorial flow (SCEF) intensifies the moisture transportation from tropical oceans to the continent and led to the summer rainfall anomalies in East Asia [12]. 
As pointed by Xue et al. [13], the seasonal transition in SH first begins in the high latitudes. Through the "sea-saw" structure of AAO, the extratropical circulation affects the EASM through changing the subtropical highs. This result has been validated by recent studies. AAO can also be used as a predictor in seasonal forecast operation. For example, following a strong AAO in boreal spring, both the $\mathrm{MH}$ and the AH enhance, and more summer rainfall occurs from the Yangtze River valley in China to Japan. So besides ENSO, AAO is another precursory signal for the interannual variation of summer rainfall in East Asia [14]. Among different influencing processes, the SCEF plays a key role and its interannual variability is tightly linked with the abnormal wave trains along the coast of East Asia. Stronger (weaker) SCEF always relates to less (more) summer rainfall in the south of the Yangtze River valley [12].

Based on the analysis of mean meridional circulation, it is found the positive AAO anomaly will weaken the cold air activity over East Asia during both boreal winter and spring through barotropic meridional teleconnection from the Antarctic to the Arctic [15]. This teleconnection is remarkable over Eurasia in winter and over the Pacific Ocean in spring. The result indicates the local meridional teleconnection is possibly a linkage of the interaction of atmospheric circulation over the middle and high latitudes between the two hemispheres. This conclusion has been validated by numerical simulation [16]. A case study of 2005/2006 also suggests that a weaker AAO in boreal winter is favorable for more Mongolia cyclones and strengthens the surface gales in spring, resulting in more frequent dust storm events in northern China [17]. Owing to these results, the AAO has been widely included in statistical models of seasonal forecast in China [18-20]. Besides the impact on the climate in East Asia, the AAO can also exert great an influence on the North American summer monsoon [21] and the West Africa summer monsoon [22].

Results of the South China Sea monsoon experiment (SCSMEX) show that the ASM starts first over the IndoChina Peninsula (ICP) and the South China Sea (SCS) [23]. Its onset date has been regarded as an important indicator for the beginning of both the seasonal transition from winter to summer and the flood season in Asia. Researches also indicate that the precursory influencing factor of ASM can be related to the SCEF in boreal spring. Before the onset of ASM, the SCEF experiences an abrupt increase, which impels an eastward propagation of the westerly flow over the Bay of Bengal (BOB), and promotes an eastward withdrawal of the western Pacific subtropical high (WPSTH) from the SCS to the western Pacific, triggering the burst of ASM. As mentioned above, the $\mathrm{SH}$ subtropical high has a close relationship with the SCEF [14]. Since the pressures in the subtropics and higher latitudes in the $\mathrm{SH}$ have opposite variations, can the influencing factors of ASM be extended more southward to the South Pole area, i.e. the high-latitude branch of the AAO? On the other hand, the seasonal fore- cast of summer climate should be issued in April owing to the service requirements of decision makers and the government, meaning that the complete dataset of spring is not available before making the prediction. So, it is necessary to seek new predictors in the previous winter for ASM forecast.

\section{Data description and definition of AAO index}

The primary dataset used in this study is the NCEP/NCAR monthly and daily reanalysis products including sea level pressure (SLP), 500-hPa geopotential height, 850-hPa zonal and meridional winds, and outgoing long-wave radiation (OLR) on a $2.5^{\circ} \times 2.5^{\circ}$ latitude-longitude grid for 1979-2011 [24]. Time series of the onset date of South China Sea summer monsoon (SCSSM) during the same period from the National Climate Center (NCC) of China is also analyzed. In the operation of SCSSM monitoring, the onset date is defined as the first pentad in which the zonal wind at $850 \mathrm{hPa}$ averaged over $10^{\circ}-20^{\circ} \mathrm{N}, 110^{\circ}-120^{\circ} \mathrm{E}$ changes from easterly to westerly, and the mean pseudo-equivalent potential temperature at the same level and region decreases to $340 \mathrm{~K}$. Beside these two objective judgments, the WPSTH are also considered in determining the monsoon onset date.

Two methods have been used to define the AAO index in previous studies. The first definition is based on the pressure difference between the subtropics and high latitudes in the $\mathrm{SH}$, for example, the difference in averaged SLP between $40^{\circ}$ and $65^{\circ} \mathrm{S}$ [25]. Gao [26] modified the definition to $30^{\circ}$ and $65^{\circ} \mathrm{S}$ considering the climatological position of the subtropical high center and the downward branch of the Ferrel cell. The other definition employs the time series of the first leading mode of 700-hPa geopotential height to the south of $20^{\circ} \mathrm{S}$ [27]. Monthly AAO indices since 1979 from the second definition can be obtained from the Internet at www.cpc.noaa.gov, which are used in this paper.

Figure 1 shows the normalized AAO index in boreal winter. It shows a significant (passing the 95\% confidence level) increasing trend in the analysis period. In this paper,

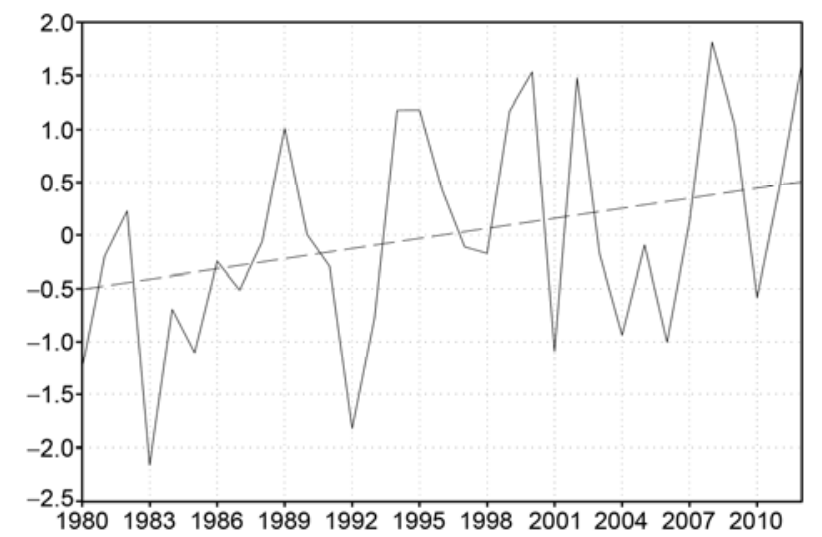

Figure 1 Normalized AAO index in boreal winter (solid curve) and its linear trend (dashed line). 
eight years with AAO indices greater than 1.0 are selected as the strong AAO years, i.e. 1989, 1994, 1995, 1999, 2000, 2002, 2008, and 2009. Another seven years with indices less than -1.0 are chosen as the weak AAO years, i.e. 1980, 1983, 1985, 1992, 2001, 2004, and 2006. To have the same number of cases as for the strong AAO years, the year 1993 is also elected as a weak case in which the index is -0.8 .

\section{Influence of AAO on ASM and possible mechanism}

As mentioned above, the Indo-China Peninsula (ICP) and the South China Sea are the regions where the ASM begins firstly. Climatologically, the ASM can be found in the 26th pentad (early May) over the eastern BOB and ICP, and in the 28th pentad (middle May) over the SCS. Since then the ASM propagates to India and the western Pacific. So in the following our analysis will be focused on the ICP and SCS summer monsoons.

To better illustrate the relationship between ASM and AAO, OLR and zonal wind are composed for strong and weak AAO years, respectively. In the strong AAO years, deep convection $\left(\mathrm{OLR} \leqslant 230 \mathrm{~W} / \mathrm{m}^{2}\right)$ can be found in late April over the ICP, especially near $100^{\circ} \mathrm{E}$. It propagates westward quickly to the eastern BOB. In early May, OLR decreases to $200 \mathrm{~W} / \mathrm{m}^{2}$ and below. Over the SCS, both deep convection and westerly flow appear in early May. Compared to the normal onset dates, both the ICP/BOB summer monsoon and the SCSSM appear earlier following strong AAO winters. According to the onset dates of SCSSM monitored by the NCC, among all the eight strong AAO years there are five years in which the SCSSM occurs before its normal date.

While in the weak AAO years, composed results indicate both deep convection and westerly flow appear later over the ICP. It can be clearly seen that OLR values are greater than $230 \mathrm{~W} / \mathrm{m}^{2}$ before early May, and convection increases in middle May. Compared to the counterpart in Figure 2(a), convection is also weaker than normal. Deep convection with OLR values less than $200 \mathrm{~W} / \mathrm{m}^{2}$ does not appear till late May. Over the SCS, deep convection and westerly flow begin in early June and late May, respectively. Different from the counterpart in strong AAO years, the beginning time of westerly flow over the SCS is not the same as the deep convection. From the monitoring results of SCSSM in the NCC, among the eight weak AAO cases there are seven years in which the SCSSM onset dates are later than normal.

In the analysis period the ASM displays an advancing onset trend. Taking the SCSSM as an example, the averaged onset date in the recent two decades is about one pentad earlier than that in previous periods. As shown in Figure 1, the AAO index in December-January-February (DJF) also shows a significant increasing trend, meaning that the relationship between AAO and ASM is similar on both interannual timescale and interdecadal timescale.

Beside the establishment of deep convection and westerly flow, another abrupt feature of ASM onset is the quick eastward withdrawal of the WPSTH. This feature is also very different in strong/weak AAO years (figures not shown). In strong AAO years, the WPSTH is weaker than normal, with the $5870 \mathrm{gpm}$ contour moving to the ocean east of $120^{\circ} \mathrm{E}$ in early May. It is hard to find the $5880 \mathrm{gpm}$ contour on the continent. While in weak AAO years, the
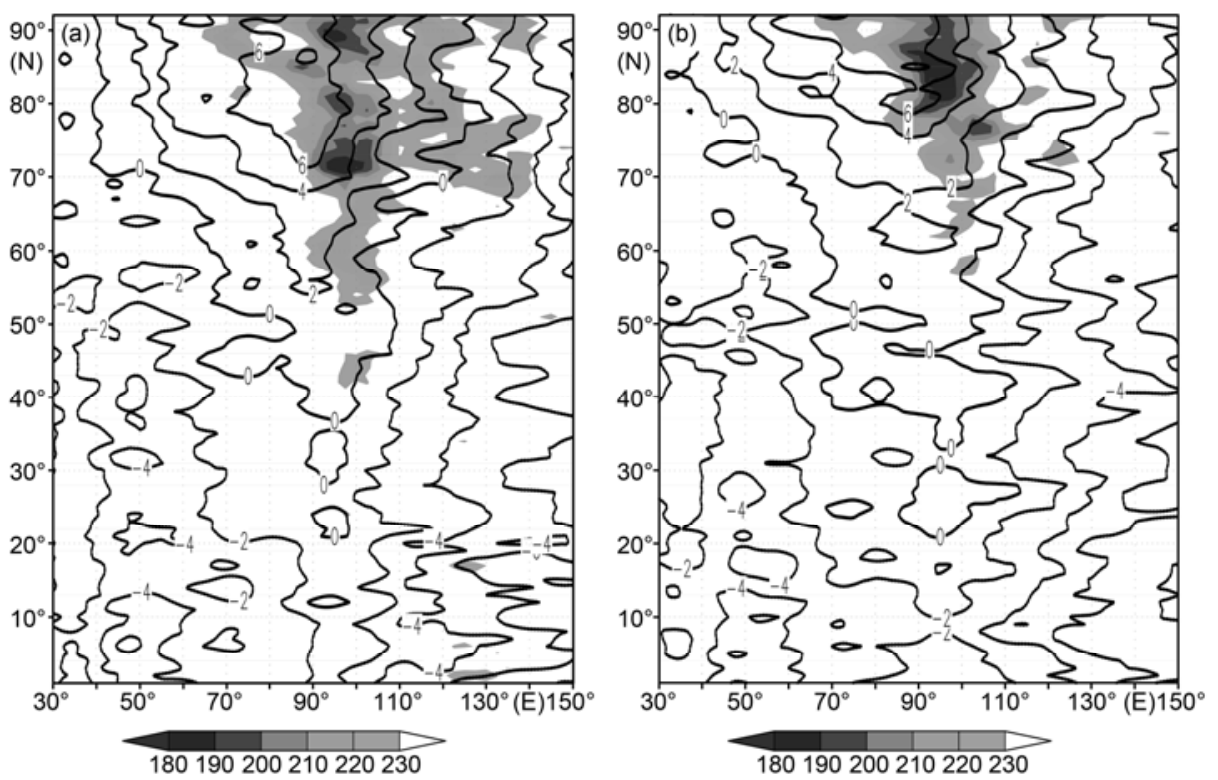

Figure 2 Composed zonal wind speed at $850 \mathrm{hPa}$ (contours, $\mathrm{m} / \mathrm{s}$ ) and OLR (shaded, W/m $\mathrm{m}^{2}$ ) averaged at $\left(5^{\circ}-20^{\circ} \mathrm{N}\right)$ in eight strong (a) and weak (b) years. Numbers in the abscissa mean the degrees of longitude. In the ordinate the number "1" means the first day of March, " 2 " means the second day of March, and so on. 
WPSTH is strong. The 5870 gpm contour lies over the SCS till June. This difference also indicates the precursory influence of AAO on ASM.

Previous studies have explored the pivotal role of SCEF in triggering the onset of ASM. The SCEF usually has a quick enhancement ten days, before the onset of SCSSM, impelling the quick eastward propagation of the westerly flow over the BOB and accelerating the eastward withdrawal of the WPSTH from the SCS. Following a strong and early SCEF, the SCSSM always occurs early, and vice versa. This feature means that the SCEF possibly links to both ASM and AAO. To validate this inference, correlation coefficients (CCs) are calculated between the AAO index in DJF and the meridional wind speed at $850 \mathrm{hPa}$ along the equator in March and April, respectively. In the eastern hemisphere, there exist five main CEFs including the SCEF (near $\left.45^{\circ} \mathrm{E}\right)$, the Sumatra $\mathrm{CEF}\left(85^{\circ} \mathrm{E}\right)$, the SCS CEF $\left(105^{\circ} \mathrm{E}\right)$, the western Pacific CEF $\left(125^{\circ} \mathrm{E}\right)$, and the Papua New Guinea $\mathrm{CEF}\left(150^{\circ} \mathrm{E}\right)$. In March, only the $\mathrm{CCs}$ between AAO index and SCEF intensity have exceeded the $95 \%$ confidence level because the other four CEFs have not established in this month (solid curve in Figure 3). In April, the maximum CC center is still located over the SCEF channel (dashed curve in Figure 3). Compared to the counterpart in March, its peak

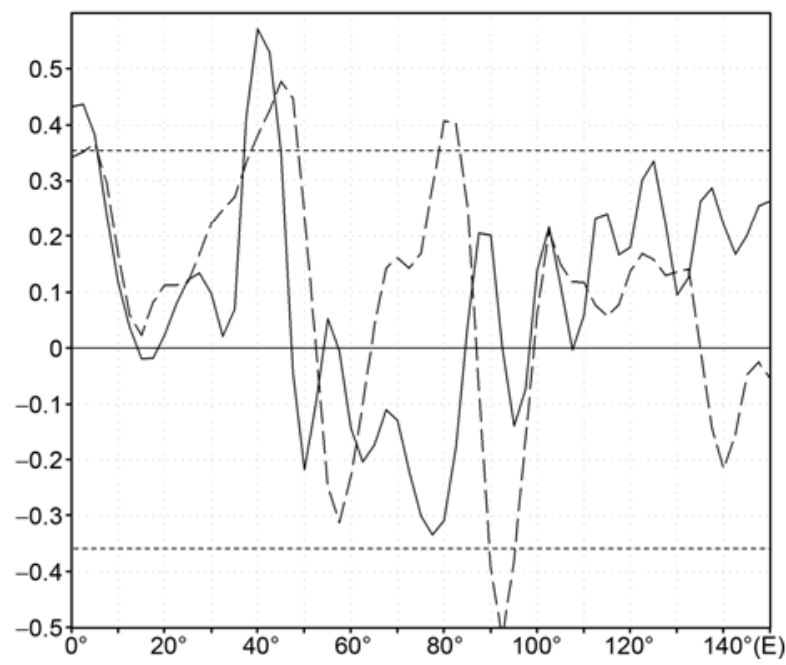

Figure 3 Correlation between the AAO index in DJF and meridional wind speed at $850 \mathrm{hPa}$ along the equator in March (solid curve) and in April (dashed curve), respectively. The two thick dashed lines mean the significant values exceeding the $95 \%$ confidence level ( $t$-test). position is more eastward because of the eastward shift of the SCEF axis in April. Another significant CC center lies over the Sumatra CEF channel, i.e. $80^{\circ}-90^{\circ}$ E. Over the other CEF channels, there is no close relationship between meridional wind speed and $\mathrm{AAO}$ index.

Composed results also support the conclusion obtained from the correlation analysis (figures not shown). In the strong AAO pattern, the southerly wind at $850 \mathrm{hPa}$ appears in middle April over the SCEF channel and maintains stably. While in the weak AAO pattern, persistent southerly flow cannot be found before early May.

Because of the effect of the Coriolis force, westerly flow prevails over the tropical Indian Ocean after the establishment of CEF. Figure 4 shows the CCs between the AAO index and the zonal wind speed at $850 \mathrm{hPa}$. Obviously, positive CCs cover all the tropical Indian Ocean in the $\mathrm{NH}$, especially over $80^{\circ}-120^{\circ} \mathrm{E}$. Similar to the role of SCEF, the tropical Indian westerly flow will also impel the eastward withdrawal of the WPSTH, enhance the convergence and rising motion at lower troposphere, and accelerate the burst of deep convection over Asia.

The influencing process of AAO on ASM can be explained from Figure 5. It shows the CCs between the SLP in March and the AAO index in DJF. Significant negative CCs appear over all tropical regions while positive values over the subtropical regions in SH. This correlation pattern means that the strong AAO in boreal winter will strengthen the subtropical high, deepen the intertropical convergence zone (ITCZ) in early spring, and then increase the pressure gradient between these two systems. Thus the SCEF will begin earlier in spring and enhance the westerly flow over the tropical India Ocean. Different from the strong AAO, weak AAO will weaken the pressure gradient between tropical and subtropical regions and delay the establishment of CEFs.

Undoubtedly, ENSO is another crucial external factor affecting the ASM besides AAO. To better reveal their individual contribution to the onset of ASM, partial correlation is employed in this study. Results indicate that the partial correlation coefficient (PCC) between the Niño3.4 index in DJF and the SCSSM onset date is 0.05 without AAO, while the value is -0.17 without ENSO. Though both PCCs cannot significantly exceed the $95 \%$ confidence level, the results still suggest the importance of AAO for the onset of ASM.

In this paper, more attentions have been paid to the Indian

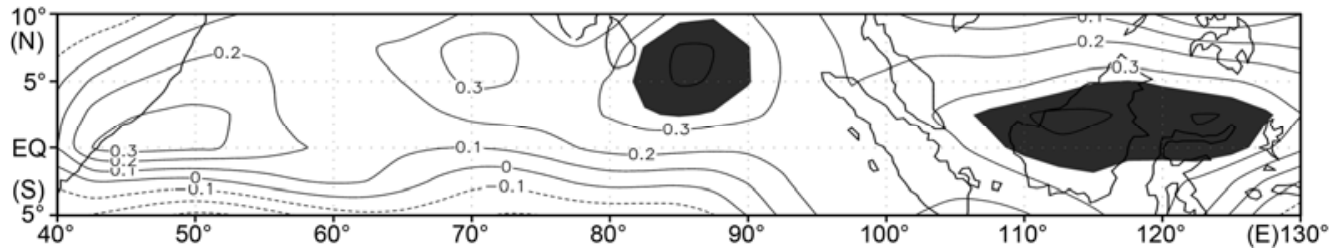

Figure 4 Correlation between the AAO index in DJF and the zonal wind speed at $850 \mathrm{hPa}$ in April. Shaded are significant values exceeding the $95 \%$ confidence level ( $t$-test) 


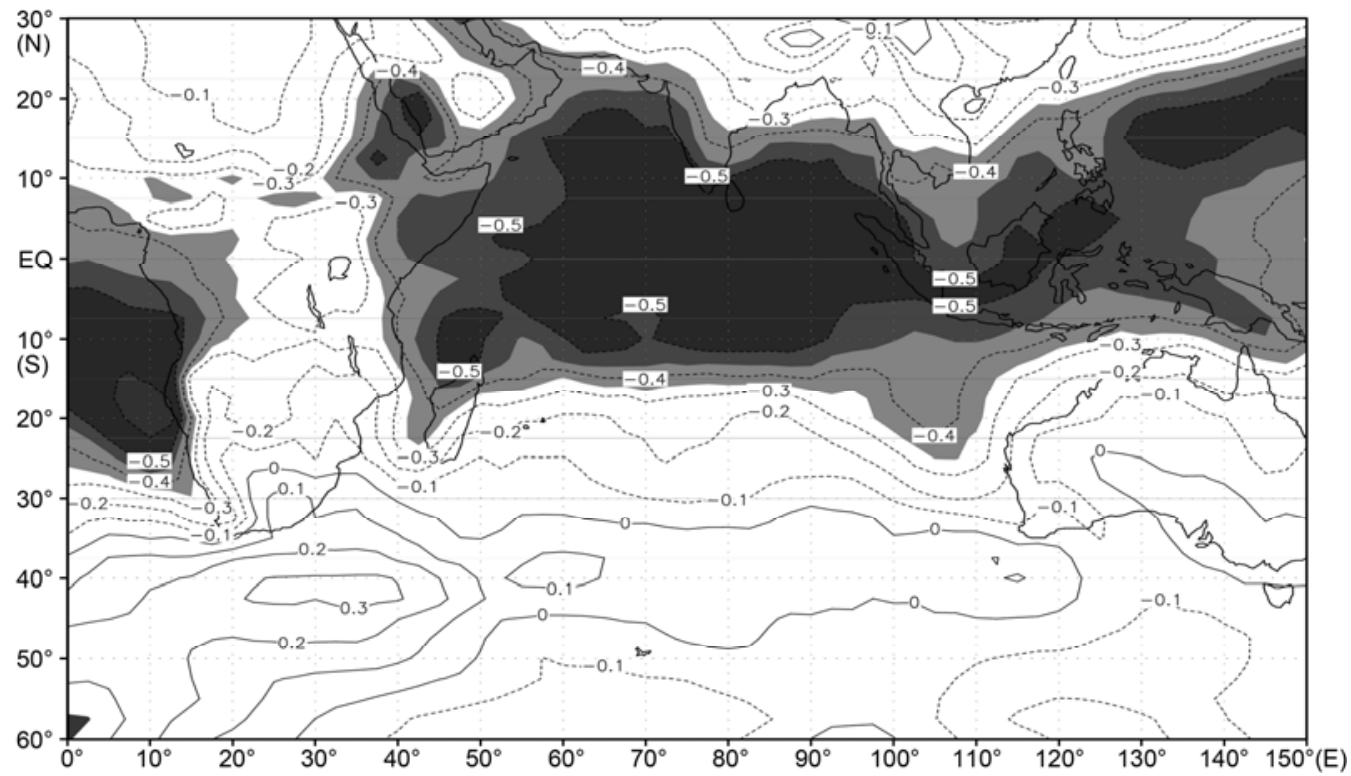

Figure 5 Correlation between the AAO index in DJF and the SLP in March. Shaded are significant values exceeding the 95\% confidence level ( $t$-test).

Ocean to illustrate the primary influencing process. However, uncertainty exists in the process, such as the role of the Pacific Ocean. In the strong AAO winter, the SST pattern over the tropical Pacific shows a La Nina-like mode. This pattern is also favorable for an earlier ASM in the following spring. Nevertheless, the interaction between AAO and ENSO in winter is unclear at present. Thus, further analysis about the role of the Pacific Ocean is necessary for better understanding the physical mechanism.

\section{Conclusions}

Statistical results indicate a significant influence of AAO in boreal winter on the onset of ASM and that AAO can be used as a premonitory predictor. Owing to the "see-saw" structure of the atmospheric circulations in the subtropics and higher latitudes in the $\mathrm{SH}$, both the $\mathrm{MH}$ and the $\mathrm{AH}$ in March are stronger followed a stronger AAO in winter. In the meantime the ITCZ is deeper in the tropics. Under this pattern, the pressure gradient between the subtropical and tropical regions increases in spring. Thus, the SCEF strengthens and begins earlier. As a result of the effect of the Coriolis force, westerly flow prevails over the tropical Indian Ocean earlier than normal, after the establishment of CEF. The enhanced westerly flow impels an eastward withdrawal of the WPSTH and enhances the convergence and rising motion at the lower troposphere, accelerating the burst of deep convection in Asia. Differently, a weaker AAO weakens the pressure gradient between the tropical and subtropical regions and delays the establishment of CEF, thus delaying the onset of ASM.

Previous studies have analyzed the premonitory predictor of ASM and found several possible indicators in the atmos- pheric circulation in tropical and subtropical $\mathrm{SH}$ in boreal spring such as the $\mathrm{MH}$ and the $\mathrm{AH}$. However, owing to the service requirements of decision makers and the government, the seasonal forecast of summer climate is issued in April. So, it is necessary to seek a new predictor in the previous winter for ASM forecast. Results in this paper provide such a new precursory predictor and can be used in the operation of seasonal forecast.

Many thanks to the reviewers and Dr. Song Yang at CPC/NOAA for their valuable comments and suggestions. This work was supported by the National Basic Research Program of China (2012CB417205), the International Cooperation Program of Ministry of Science and Technology of China (2009DFA23010), the Special Research Fund of Public Welfare Project (Meteorology: GYHY200906018 and GYHY201306070), and the National Science \& Technology Supporting Program (2009BAC51B). The authors also thank the support of the National Innovation Team of Climate Prediction of China Meteorological Administration.

1 Walker G T. World weather. Quart J Res Meteorol Soc, 1928, 54: 79-87

2 Montgomery R B. Report on the work of G T Walker. Mon Weather Rev, 1940, 39: 1-22

3 Van Loon $\mathrm{H}$. The half-yearly oscillations in middle and high southern latitudes and the coreless winter. J Atmos Sci, 1967, 24: 472-486

4 Rogers J C, Van Loon H. Spatial variability of sea level pressure and $500 \mathrm{mb}$ height anomalies over the Southern Hemisphere. Mon Weather Rev, 1982, 110: 1375-1392

5 Mo K C, White G N. Teleconnections in the Southern Hemisphere. Mon Weather Rev, 1985, 113: 22-37

6 Tao S Y, Xu S Y, Guo Q Y. The characteristics of the zonal and meridional circulation over tropical and subtropical regions in Eastern Asia in summer (in Chinese). Acta Meteorol Sin, 1962, 32: 91-103

7 Chen L X. Structure of the East Asian monsoon system and its medium-range oscillation (in Chinese). Acta Oceanol Sin, 1984, 1: 744-758

8 Wang S W, Zhao Z C. Basic Knowledge of the Long-Term Weather Forecasts (in Chinese). Shanghai: Shanghai Science and Technology 
Press, 1987. 201

9 Huang S S, Tang M M. Medium-range oscillation of the atmospheric circulation systems over the northwestern Pacific and southern Indian Oceans and their telecorrelation (in Chinese). Sci Meteorol Sin, 1988, 8: $1-13$

10 Yang X Q, Huang S S. The numerical experiment on the influence of Mascarene High intensity variation on the atmospheric circulation (in Chinese). Sci Meteorol Sin, 1989, 9: 125-137

11 He J H, Chen L Z. Quasi-forty days oscillation over the mid-latitude of the Southern Hemisphere with their relation to the summer monsoon over the Northern Hemisphere (in Chinese). J Nanjing Inst Meteorol, 1989, 12: 11-18

12 Wang H J, Xue F. Interannual variability of Somali Jet and its influences on the inter-hemispheric water vapor transport and on the East Asian summer rainfall (in Chinese). Chin J Geophys, 2003, 46: 18-25

13 Xue F, Lin Y H, Zeng Q C. On the seasonal division of atmospheric general circulation and its abrupt change, Part III: Climatology (in Chinese). Chin J Atmos Sci, 2002, 26: 308-314

14 Xue F, Wang H J, He J H. The interannual variation of the Mascarene High and Australia High and its influence on the East Asian monsoon precipitation. Chin Sci Bull, 2003, 48: 287-291

15 Fan K, Wang H J. The interannual variation of the Antarctic oscillation and its influence on the East Asian climate in winter and spring. Sci China Ser D-Earth Sci, 2006, 36: 308-314

16 Fan K, Wang H J. Simulation of the AAO anomaly and its influence on the Northern Hemispheric circulation in boreal winter and spring (in Chinese). Chin J Geophys, 2007, 50: 397-403

17 Fan K, Wang H J. The weakening of the Antarctic oscillation and the dust climate during spring 2006 in China (in Chinese). Clim Environ Res, 2007, 12: 475-480
18 Fan K, Wang H J. The Antarctic oscillation anomaly and summer precipitation prediction over East China in 2006 (in Chinese). J Appl Meteorol Sci, 2006, 17: 383-384

19 Fan K, Wang H J, Choi Y J. A physically-based statistical forecast model for the middle-lower reaches of the Yangtze River Valley summer rainfall. Chin Sci Bull, 2008, 53: 602-609

20 Sun J Q, Wang H J, Yuan W. A possible mechanism for the covariability of the boreal spring Antarctic Oscillation and the Yangtze River valley summer rainfall. Int J Climatol, 2009, 29: 1276-1284

21 Sun J Q. Possible impact of the boreal spring Antarctic oscillation on the north American summer monsoon. Atmos Ocean Sci Lett, 2010, 3: $232-236$

22 Sun J Q, Wang H J, Yuan W. Linkage of the boreal spring Antarctic oscillation to the west African summer monsoon. J Meteorol Soc Jpn, 2010, 88: 15-28

23 Ding Y H, Li C Y, He J H, et al. South China Sea Monsoon experiment (SCSMEX) and the East-Asian Monsoon (in Chinese). Acta Meteorol Sin, 2004, 62: 561-586

24 Kalnay E, et al. The NCEP/NCAR 40-year reanalysis project. Bull Amer Meteorol Soc, 1996, 77: 437-471

25 Gong D Y, Wang S W. Definition of Antarctic oscillation index. Geophys Res Lett, 1999, 26: 459-462

26 Gao H. Seasonal and interannual variations of the circulations in Southern Hemisphere and their influences on East Asian summer monsoon (in Chinese). Dissertation for the Doctoral Degree. Nanjing: Nanjing University of Information, Science and Technology, 2004. $1-162$

27 Thompson D W J, Wallace J M. Annular modes in the extratropical circulation, Part I: Month-to-month variability. J Clim, 2000, 13: $1000-1016$

Open Access This article is distributed under the terms of the Creative Commons Attribution License which permits any use, distribution, and reproduction in any medium, provided the original author(s) and source are credited. 